\title{
COVID-19 seroprevalence study of an Indian Diagnostic Laboratory - Report on gender and age analysis
}

\author{
Kallathikumar Kallathiyan, Amruta Velumani, Sandhya Iyer*, Krishnakumar Sivapandi, Anand Velumani
}

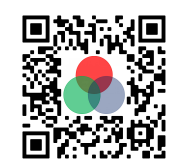

Use your smartphone to scan this QR code and download this article

\begin{abstract}
In COVID-19 the extent of the impact on exposure, symptoms, recovery remains minimally explored as the spectrum is challenging to study across geographies. The aim of our study report was to explore seroprevalence in a pan-India cohort of Asian Indians across different age groups. Covid-19 antibodies were tested from a total of 1,36,210 Asian Indians inclusive of 97,124 males and 39,086 females, respectively. Testing for covid-19 antibodies was done by electrochemiluminescence immunoassay (ECLIA) and enzyme-linked immunosorbent assay (ELISA). Analysis for seroprevalence found the frequency to be $19 \%$. The percent positives were higher among females at $21 \%$, compared to males at 19\%, and the difference was found to be statistically significant at $p<0.0001$. Further, age group-wise analysis found seroprevalence between age groups of 21 - 80 years to be significant at $p<0.0001$. Our study found higher seroprevalence among females, which is in line with many small cohort studies published online.
\end{abstract}

Key words: Antibody, Coronavirus, COVID-19, Females, India, Males, Pandemic
Immunoassay Division, Thyrocare Technologies Limited, Plot

No.D37/1,TTC Industrial area, MIDC,

Turbhe, Navi Mumbai - 400703, India

\section{Correspondence}

Sandhya Iyer, Immunoassay Division Thyrocare Technologies Limited, Plot No.D37/1,TTC Industrial area, MIDC Turbhe, Navi Mumbai - 400703, India

Email: sandhya.iyer@thyrocare.com

\section{History}

- Received: 2020-10-05

- Accepted: 2020-10-27

- Published: 2020-11-10

DOI : 10.15419/ajhs.v6i2.478

\section{Check for updates}

\section{Copyright}

( $)$ Biomedpress. This is an openaccess article distributed under the terms of the Creative Commons Attribution 4.0 International license.

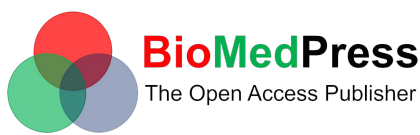

age group of 60 - 79 years to be the most vulnera-

\section{INTRODUCTION}

The coronavirus disease of 2019 (COVID-19) caused by the SARS-CoV-2 has had an enormous impact on global healthcare infrastructure. The social impact of the pandemic include, loss of livelihood for many, apart from anxiety around the cause for fatality. Apart from understanding the mechanism of infection, determining risk factors on the cause, and the spread of the pandemic has generated heterogeneous information deluge. The delay in making available testing kits, variations in diagnosis criteria, the inherent risk around sample collection for reverse transcriptasepolymerase chain reaction test (RT-PCR), and implementation of different intervention strategies at different stages of the pandemic has made epidemiological data comparison even within the country, a difficult task. Answers to a lot of questions around the spectrum of disease severity ranging from asymptomatic to a mild symptomatic, severe disease requiring hospitalization and fatality are critical ${ }^{1}$. The recurring incidences of coronavirus infection first in the year 2003, and then 2012, and the current 2019, has been overwhelming both in terms of healthcare management, through its mode of transmission, higher risk of death among the vulnerable, increased risk for healthcare workers, and the significant number of deaths ${ }^{2}$. In the case of India, one report by the Indian Council of Medical Research (ICMR) highlighted the ble, with $51.2 \%$ having succumbed to covid-19 being over 60 years of age ${ }^{3}$. Another following report from New Delhi detected $43 \%$ of the covid-19 deaths to have taken place in the younger age groups of between $30-44$ years and 45 - 59 years, respectively ${ }^{4}$. The wide spectrum in the age group around the fatality of covid-19 in the country does add to a lot of epidemiological dilemma wherein risk stratification becomes difficult.

In the case of diagnosis of covid-19, RT-PCR has been recommended, and many comparison studies have detected molecular analysis to be better in terms of sensitivity and specificity. The type of specimen tested and the time period has been shown to impact diagnosis with RT-PCR, as early period serum samples were detected to be negative, while the respiratory specimen was positive ${ }^{5}$. Pre-analytical and analytical variables have been shown to highly impact diagnostic accuracy of RT-PCR, including quality of the sample, wherein sputum has been detected to be better than oropharynx, which is superior to the nasophar$y_{n x}{ }^{6}$. Testing for total (IgG and IgM) covid-19 antibodies adds convenience to the sampling process and feasibility to use for large scale population monitoring. The added advantage of studying covid-19 antibodies lies in the general efficacy of the serological assays among late presenting patients and those with low viral load ${ }^{7}$. Antibody tests have been viewed as an 
excellent companion for RT-PCR tests in SARS-CoV2 as they aid in identifying asymptomatic individuals. Though the window period for antibody testing in covid-19 is debated to lie between 10 - 14 days after symptom onset, they are important for epidemiological investigations to monitor the extent and prevalence of infection ${ }^{8}$.

The aim of the present study was to assess the seroprevalence for the covid-19 antibody in a pan-India cohort of Asian Indians across different age groups. This is crucial for risk stratification and designing public health measures. A nationwide serosurvey that is targeting specific strata, including different age groups and gender, will aid in determining the impact of containment measures, as well as behavioral changes. An age group serosurvey analysis also aids in determining the high-risk category and identifying the mode of transmission across different subsections of society.

\section{MATERIALS - METHODS}

This observational report includes data from samples processed in a reference laboratory and not a hospitalbased setting. No patient identifiers have been used in any part of this report, and hence the need for informed consent and review board approval does not fit as a necessity. Data from a total of 136,210 samples tested for the covid-19 antibody assay have been used for this analysis.

Total covid-19 antibody testing was done by the technology of electrochemiluminescence immunoassay (ECLIA), and that for IgG was done by enzyme-linked immunosorbent assay (ELISA). The approved commercial kits for ECLIA include the Cobas Elecsys Anti-SARS-CoV-2 (Roche Diagnostics, GmbH) and the SARS-CoV-2 Total (COV2T, Siemens Healthcare Diagnostics Inc., USA). The approved commercial kits for ELISA include the COVID-19 IgG ELISA Kit (Omega Diagnostics, UK) and ErbaLisa COVID-19 IgG (Calbiotech Inc. USA). The ECLIA assay involved the use of a recombinant protein representing the nucleocapsid $(\mathrm{N})$ antigen to detect antibodies against the SARS-CoV-2, and also a sandwich immunoassay using acridinium ester chemiluminescent technology. In the case of ELISA, the principle was a semi-quantitative plate-based assay to detect COVID19 IgG antibodies. Result interpretation was made using the cutoff index (COI) as specified by the manufacturer.

\section{RESULTS}

A total of 136,210 serum samples were assessed for the covid-19 antibody, including 97,124 males and 39,086 females. The seroprevalence found in our analysis was $19 \%$. In case of females the percent positive was found to be higher at $21 \%$, compared to males at $19 \%$, and the difference was statistically significant at $\mathrm{p}<0.0001$. Further, age group analysis was also done to understand if there was any difference in seroprevalence, impacting age-related susceptibility. The results have been summarized in Table 1.

Analysis of significance in seroprevalence between different age groups found the difference in percent positive between age groups of $21-80$ years to be significant at $\mathrm{p}<0.0001$. The seroprevalence of above $20 \%$ was found in the age group of $>40$ years. Our analysis also found the age group of between $61-80$ years to exhibit maximum exposure.

Further analysis of gender among different age groups found the percent positive difference between males and females to be significant up till 60 years of age at $\mathrm{p}=0.0025$ among children and adolescents, while at $\mathrm{p}<0.0001$ for the adults. Maximum exposure among both males and females was detected in the age group of between 61 - 80 years. The seroprevalence was found to be consistently high among adult females in the cohort.

\section{DISCUSSION}

The covid-19 pandemic continues to evolve in terms of disease severity, recovery, and fatality rates. The developed nations of the world are challenged by high death per million (DPM), while the economically weaker geographies are under pressure to tackle the high volume of testing, to effectively control infection spread. The pandemic has posed many challenges, from the need to identify the spectrum of disease severity to studying transmission and rates, and lastly, the factors that promote the risk of fatality from severe illness stage ${ }^{1}$. Age has been classified as one of the risk factors for infection, and many studies have identified the risk of infection among the elderly to be affected by other age groups ${ }^{9,10}$. Studies on contact rate, and infection transmission across different age groups, have detected the old age group to be susceptible, and the impact of social distancing on pandemic control to depend on the role of different age groups in transmission ${ }^{9}$.

Age group analysis becomes a crucial factor in many epidemiological aspects of covid-19, right from charting exposure to susceptibility, contact tracing, and rate of transmission. Adaptive immunity, which determines exposure as well as susceptibility index in a population, also becomes a crucial factor to study pandemic control. India has vast geography, and a few metro cities have contributed to over $50 \%$ of 
Table 1: Age group analysis for covid-19 antibody prevalence in Asian Indians

\begin{tabular}{llll}
\hline Age group (Years) & Total \%P & Males Positive & Females Positive \\
$<20$ & $18 \%(1643)$ & $18 \%(1057)$ & $16 \%(586)$ \\
$21-40$ & $17 \%(12790)$ & $16 \%(9070)$ & $19 \%(3720)$ \\
$41-60$ & $22 \%(8969)$ & $21 \%(6151)$ & $24 \%(2818)$ \\
$61-80$ & $26 \%(2472)$ & $26 \%(1612)$ & $25 \%(860)$ \\
$>80$ & $25 \%(158)$ & $25 \%(87)$ & $25 \%(71)$ \\
\hline
\end{tabular}

Note: \% - Percent positive for covid-19 antibody

the total caseload in the country, including Mumbai, and Pune from Maharashtra, Delhi, Ahmedabad from Gujarat, and Jaipur from Rajasthan and Chennai from Tamil Nadu ${ }^{11}$. Seroprevalence analysis in a countrywide aspect can play a crucial role in identifying the success of existing pandemic control measures. Our study's aim was to assess the seroprevalence of covid19 antibodies across different age groups in a panIndia population. The samples included those from the general population, including working professionals, and the total percent positive found in our study was $19 \%$. In comparison, a study on 60,000 participants from Spain detected seroprevalence to be low at 5\%, while a Swiss study which assessed 2766 specimens found the same to be around $10.8 \%^{12,13}$. The earliest seroprevalence study which was done in the epicenter of covid-19; Wuhan, after $4-8$ weeks of peak infection, found the frequency to be low at $3.8 \%{ }^{14}$. Similar seroprevalence reports from 10 sites in the United States detected the prevalence to range between $1 \%$ to $6.9 \%{ }^{15}$. The seroprevalence detected by our study in India is higher in comparison to many other countries, and this can also be the attributable factor for the low DPM ${ }^{16}$.

A seropositive survey across different age groups, including young children to adults, and older population, was also included. Our study detected the seroprevalence to be significant between age groups of $21-80$ years at $\mathrm{p}<0.0001$. Government data indicated $85 \%$ of covid-19 deaths to occur among the 45-plus years age population ${ }^{17}$. Published reports highlight an association between fatality rates, and age-associated susceptibility, though our seroprevalence study indicates good percent positives in all the age groups studied. Our findings can also be compared with another Indian report on seroprevalence from Mumbai and Delhi done in early July 2020. This report, which studied IgG prevalence, detected the positive to be $23 \%$ in Delhi, while in Mumbai, the frequency was higher at $57 \%$ in the slum areas and $16 \%$ in the non-slum localities. Assuming $40 \%$ of the city's population in Mumbai to reside in slum areas, a prevalence of roughly $33 \%$ was cited as of the time of the survey ${ }^{18}$. A recent serosurvey report by ICMR has estimated 1 in 15 above the age of 10 years to have been exposed to the SARS-CoV-2 by August 2020. This report also highlighted an increasing trend noted in seropositive from $23.5 \%$ in July to $29.1 \%$ in August ${ }^{19}$. A recent serosurvey report by the Bombay Municipal Corporation, Tata Institute of Fundamental Research, and Niti Aayog identified the age group of between 41-60 years to be the most exposed in Mumbai ${ }^{20}$.

Gender analysis was also done to identify seroprevalence differences, if any, across males and females. Our study detected the difference in percent positive between males and females to be significant between $21-60$ years of age at $p<0.0001$. The frequency of seropositive was higher among females. An Indian report on the lines of stating covid infection to double among males over females further stated age group of between 19 - 35 years to be more affected. The data further indicated the death rate to be $68 \%$ among males and $32 \%$ among females ${ }^{21}$.

\section{CONCLUSIONS}

Under-reporting of data across age groups can greatly impact the outcome of social distancing and other pandemic control measures. A seroprevalence study to a great extent can aid in assessing epidemiology surveillance, and when data across different age group is made available, informed choices behind easing lockdown strategies becomes easier. The data utilized for this report though, has a pan-India representation; there have been no statistical calculations around determining the right cohort size or population selection. Since the purpose of this report revolves around highlighting the findings of a national diagnostic laboratory, the concerns around sample bias have not been met adequately. The study we believe is one of the first few large scale Indian reports to focus on covid-19 seroprevalence across different age groups, 
and we detected females to be higher in percent positive than males, and the prevalence to be comparable across different age groups.

\section{LIST OF ABBREVIATIONS}

COI - Cutoff Index

COVID-19 - Coronavirus disease of 2019

DPM - Death Per Million

ECLIA - Electrochemiluminescence Immunoassay

ELISA - Enzyme-Linked Immunosorbent Assay

ICMR - Indian Council of Medical Research

RT-PCR - Reverse Transcriptase - Polymerase Chain

Reaction

\section{CONFLICT OF INTEREST}

All authors are employees of Thyrocare Technologies Limited. However, no compensation has been received for this study, and hence no aspect that can be construed as a potential conflict of interest exists.

\section{ACKNOWLEDGMENTS}

The authors would like to acknowledge the contribution of Mr. Rajkumar Kushawaha, laboratory head of ECLIA for his technical expertise in facilitating COVID-19 antibody testing. The authors would also like to extend their acknowledgment to Dr. Prachi Sinkar, for her role in overseeing the technical aspects of testing and coordinating for a publication on the same.

\section{REFERENCES}

1. Lipsitch M, Swerdlow DL, Finelli L. Defining the epidemiology of Covid-19 - Studies needed. N Engl J Med. 2020;382:1194 -1196. PMID: 32074416. Available from: https://doi.org/10. 1056/NEJMp2002125.

2. Chatterjee P, Nagi N, Agarwal A, Das B, Banerjee S, Sarkar S, Gupta N, Gangakhedkar RR. The 2019 novel coronavirus disease (COVID-19) pandemic: A review of the current evidence. Indian J Med Res. 2020;151:147-159. PMID: 32362642. Available from: https://doi.org/10.4103/ijmr.IJMR_519_20.

3. 60 - 79 age group most vulnerable to Covid-19, shows stats. Cited 27 June 2020. Indian Express. 2020a;Available from: https://www.newindianexpress.com/states/kerala/2020/jun/27/ 60-79-age-group-most-vulnerable-to- covid-19-show-stats2161931.html.

4. $43 \%$ of Covid-19 deaths in India in $30-59$ yrs age band. Cited 10 July 2020. The Times of India. 2020;Available from: https: //timesofindia.indiatimes.com/india/43-of-covid-19-deathsin-india-in-30-59-yrs-age-band/articleshow/76882684.cms.

5. Pang J, Wang MX, Ang IYH, Tan SHX, Lewis RF, Chen Jl, Gutierrez RA, Gwee SXW, Chua PEY, Yang Q, Ng XY, Yap RKS, Tan HY, Teo YY, Tan CC, Cook AR, Yap JC, Hsu LY (2020) Potential rapid diagnostics, vaccine and therapeutics for 2019 novel coronavirus (2019-nCoV): A systematic review. J Clin Med;9:623. PMID: 32110875. Available from: https://doi.org/10.3390/ jcm9030623.

6. Woodcock A. Expert comment on different types of testing for COVID-19. Cited 31 March 2020. In: Science Media Centre. 2020; Available from: https://www.sciencemediacentre.org/e xpert-comment-on-different-types-of-testing-for-covid-19/.
7. Padoan A, Cosma C, Sciacovelli L, Faggian D, Plebani M. Analytical performances of a chemiluminescence immunoassay for SARS-CoV-2 IgM/lgG and antibody kinetics. Clin Chem Lab Med. 2020;58(7):1081-1088. PMID: 32301749. Available from: https://doi.org/10.1515/cclm-2020-0443.

8. Vardas E. Antibody tests aren't a COVID-19 panacea. But they're a useful additional tool. Cited 19 July 2020. 2020;Available from: In:TheConversation.Availableviahttps: //theconversation.com/antibody-tests-arent-a-covid-19panacea-but-theyre-a-useful-additional-tool-142516.

9. Hay JA, Haw DJ, Hanage WP, Metcalf CJE, Mina MJ. Implications of the age profile of the novel coronavirus. Cited 2 August 2020. 2020;Available from: https://dash.harvard.edu/ handle/1/42639493.

10. Yu X. Risk interactions of coronavirus infection across age groups after the peak of COVID-19 epidemic. Int J Environ Res Public Health. 2020;17:5246. PMID: 32708118. Available from: https://doi.org/10.3390/ijerph17145246.

11. Top 5 coronavirus-hit cities account for nearly $50 \%$ of India's Covid-19 cases. Cited 13 June 2020 Cited 13 June 2020. Hindustan Times. 2020a;Available from: https://www.hindustantimes.com/india-news/top-5coronavirus-hit-cities-account-for-nearly-50-of-india-scovid-19-cases/story-mdwaBt07cOKozkv7y6NE3J.html.

12. Pollán $M$, Pérez-Gómez $B$, Pastor-Barriuso R. Prevalence of SARS-CoV-2 in Spain (ENE-COVID): a nationwide, populationbased seroepidemiological study. Lancet. 2020;Available from: https://doi.org/10.1016/S0140-6736(20)31483-5.

13. Stringhini S, Wisniak A, Piumatti G. Seroprevalence of antiSARS-CoV-2 lgG antibodies in Geneva, Switzerland (SEROCoVPOP): a population-based study. Lancet. 2020;Available from: https://doi.org/10.1016/S0140-6736(20)31304-0.

14. XuX, Sun J, Nie S. Seroprevalence of immunoglobulin M and G antibodies against SARS-CoV-2 in China. Nat Med. 2020;PMID: 32504052. Available from: https://doi.org/10.1038/s41591020-0949-6.

15. Havers FP, Reed C, Lim T, Montgomery JM, Klena JD, Hall AJ, Fry AM, Cannon DL, Chiang C, Gibbons A, Krapiunaya I, Morales-Betoulle M, Roguski K, Rasheed M, Freeman B, Lester S, Mills L, Carroll DS, Owen SM, Johnson JA, Semenova V, Blackmore C, Blog D, Chai SJ, Dunn A, Hand J, Jain S, Lindquist S, Lynfield R, Pritchard S, Sokol T, Sosa L, Turabelidze G, Watkins SM, Wiesman J, Williams RW, Yendell S, Schiffer J, Thornburg NJ (2020) Seroprevalence of antibodies to SARS-CoV-2 in 10 sites in the United States, March 23 - May 12. JAMA Internal Medicine. 2020;PMID: 32692365. Available from: https://doi.org/10.1001/jamainternmed.2020. 4130https://doi.org/10.1001/jamainternmed.2020.4130.

16. https://www.worldometers.info/coronavirus/\#countries Accessed on - 2nd August 2020.

17. $85 \%$ Covid-19 deaths in 45 -plus age bracket: Govt data. Cited 10 July 2020b. Hindustan Times. 2020b;Available from: https ://www.hindustantimes.com/india-news/85-deaths-in-45-pl us-age-bracket-govt-data/story-II4EFnB7APRnLuU3MPmyZK html.

18. What do the Delhi and Mumbai sero-survey results tell us about COVID-19 in India? Cited 31 July 2020. The Wire.2020;Available from: https://thewire.in/health/delhi-mu mbai-covid-19-coronavirus-seroprevalence-survey-results.

19. It's estimated 1 in 15 people aged 10 and above exposed to SARS-CoV-2 by Aug: ICMR sero-survey (2020) Outlook. Cited 29 September 2020;Available from: https://www.outlookindia.com/newsscroll/its- estimated1-in-15-people-aged-10-and-above- exposed-to-sarscov2-byaug-icmr-serosurvey/1945488.

20. Second sero survey: 41-60 age group in Mumbai most exposed to Covid. Cited 07 October 2020. The Indian Express. 2020b;Available from: https://indianexpress.com/article/cities/ mumbai/second-sero-survey-41-60-age-group-in-mumbaimost-exposed-to-covid-6705956/.

21. COVID infection double in males than females; 19 - 35 years most affected age group: Coronavirus analysis data. 
Cited 10 July 2020. Times Now News. 2020;Available

from: https://www.timesnownews.com/india/article/covid- infection-double-in-males-than-females- 19-35- years- mostaffected-age- group-coronavirus-analysis-data/619645. 